\title{
Acute kidney injury: risk factors and management challenges in developing countries
}

This article was published in the following Dove Press journal: International Journal of Nephrology and Renovascular Disease 22 August 2016

Number of times this article has been viewed

\section{Daniela Ponce \\ Andre Balbi}

Department of Medicine, Botucatu School of Medicine, Sao Paulo, Brazil
Correspondence: Daniela Ponce Department of Medicine, Botucatu School of Medicine, Montenegro, $s / n$ UNESP - Campus de Botucatu, Sao Paulo |86|8687, Brazil

Email dponce@fmb.unesp.br

\begin{abstract}
Acute kidney injury (AKI) is a major global health problem in both developed and developing nations, negatively affecting patient morbidity and responsible for an estimated 1.4 million deaths per year. Although the International Society of Nephrology set a goal of eliminating preventable deaths from AKI by 2025, implementation of this program in developing countries presents major challenges not only because of the lack of resources but also because of the scarce data addressing the epidemiology and causes of AKI in developing countries, the limited health care resources to diagnose and treat AKI, and the poor awareness of the impact of AKI on patient outcomes.
\end{abstract}

Keywords: acute kidney injury, developing world, treatment

\section{Introduction}

Acute kidney injury (AKI) is a common disorder worldwide, occurring in more than 13 million people every year, $85 \%$ of whom live in developing countries. ${ }^{1}$ Recognizing this, the International Society of Nephrology (ISN) recently set a goal of eliminating preventable or treatable deaths from AKI by 2025 , the " 0 by 25 " initiative. ${ }^{2}$ Implementation of this program in low-resource settings (LRSs) presents major challenges for this initiative for a variety of reasons.

First, there are few data addressing the epidemiology and causes of AKI in LRSs. ${ }^{2-5}$ Second, health care resources to diagnose and manage AKI are often limited, with a lack of appropriate medications, equipment, and trained personnel. ${ }^{6-9}$ Third, governments and other institutions such as hospitals, nongovernmental organizations, and global health initiatives have not focused sufficiently on the problems of AKI..$^{2-5}$ Finally, there is limited awareness among health care workers of the problems presented by AKI in terms of diagnosis, treatment, and management..$^{2-5,8}$

Thus, developing and implementing effective strategies to eliminate preventable deaths from AKI in developing countries will require that efforts be made to better understand how to increase the awareness of AKI by health care workers and institutions. Further, it will require better understanding of how to implement innovative approaches for the early and effective treatment of AKI in the context of the local health care environment and available resources.

\section{Epidemiology of AKI in developing countries}

Despite the paucity of quality data for the epidemiology of AKI in developing countries, the prevalence of AKI in this setting is estimated to be higher than that in developed 
countries. ${ }^{2,4}$ It has been suggested that the global burden of AKI is up to 13.3 million cases per year, 11.3 million of which are in low- to middle-income countries and responsible for up to 1.4 million deaths per year. Furthermore, AKI-related problems account for up to $3 \%$ of hospital admissions in general health care facilities in LRSs. ${ }^{8}$

In industrialized nations, AKI is seldom a communityacquired disease; the condition develops primarily in hospitalized patients. In these regions, the incidence of hospital-acquired AKI exceeds that of community-acquired AKI by five- to tenfold, with AKI being reported in 7\%-18\% of hospital inpatients yearly. ${ }^{9,10}$ On the other hand, AKI commonly occurs in the community in less-developed nations. ${ }^{11}$ However, in this article, it is difficult to define the incidence of AKI, since no nationwide disease registries exist and data are usually derived from single-center experiences.

Patients with AKI in developing countries are typically younger and healthier than patients with AKI from developed countries, who generally are older and have multiple comorbid conditions. ${ }^{2,3,5,11-14}$ Children and young adults in developing countries are disproportionately affected by AKI as a result of infections, volume depletion due to severe diarrhea, pregnancy-related events, or animal envenomation. ${ }^{2}$ In these poor regions, in some series, children constituted $>15 \%$ of patients with AKI. ${ }^{15}$

Two studies from India have shown that the AKI incidence in inpatient wards and pediatric intensive care units ranged between 5\%-9\% and 25\%-36\%, respectively. ${ }^{11,12}$

In a recent study from the largest hospital in Uganda, the AKI prevalence among patients admitted with sepsis was $16 \%$, and the hospital mortality was $21 \%$ for patients with septic AKI. ${ }^{10}$

The cause of AKI can be broadly categorized as hospital acquired and community acquired (Table 1). ${ }^{9}$ The etiologic spectrum of hospital-acquired AKI in developing countries, which has been described primarily in large urban centers in these nations, is similar to the causes in more affluent countries. It includes postsurgical complications, hemorrhage, infections, septic shock, and drug toxicity. ${ }^{8,9}$ In contrast, community-acquired AKI in LRSs is mostly encountered in rural areas, and its true prevalence and leading causes are not well known, reflecting underreporting, limited diagnostic capacity, and lack of awareness by health care workers. ${ }^{4,8,9}$

Causes of AKI discussed in the literature include infections such as pneumonia, diarrhea, sepsis, and tropical illnesses such as malaria, leptospirosis, and dengue; acute glomerular diseases; obstetric complications; exacerbations of underlying kidney disease; intake of herbal remedies and
Table I Causes of AKI in developing countries

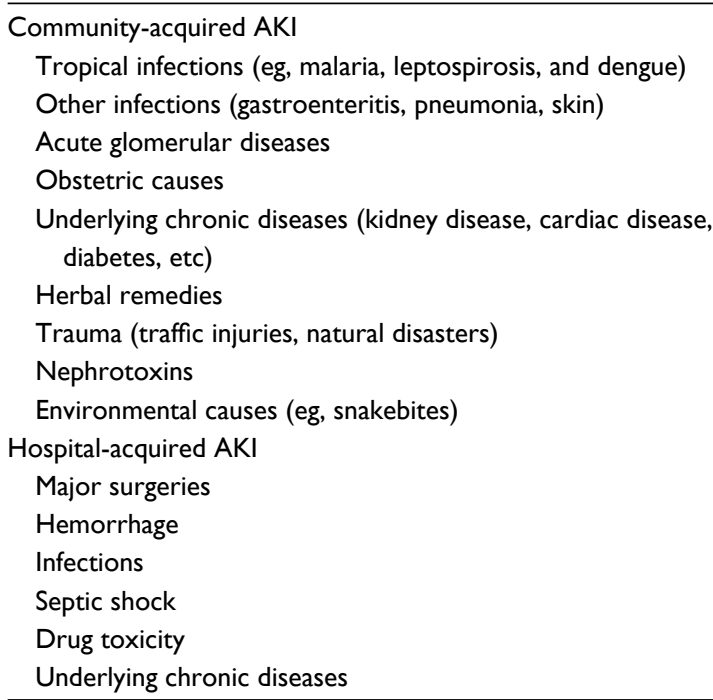

other nephrotoxins; cardiac disease; traumatic injury; and environmental exposures such as snakebites.

Although all AKI situations are tragic, the deaths of young patients with AKI in developing countries can have devastating impacts on both the economic and social structure of families. What is particularly tragic is that children and young adults continue to die in large numbers in developing countries as a consequence of this disorder, which in many cases is preventable and potentially treatable with simple measures, with few, if any, long-term health consequences. ${ }^{9}$ Those patients with acute renal failure due to acute kidney injury, who progress to the stage at which renal replacement therapy (RRT) is indicated, die because dialysis is simply not available. ${ }^{10,16}$

\section{Obstacles to diagnosis and treatment of AKI in developing countries}

There are major challenges to developing strategies to establish an early AKI diagnosis and appropriate AKI treatment in developing countries. AKI diagnosis and treatment are limited by available resources, including a lack of laboratory supplies and necessary therapeutic armamentarium and adequate medical infrastructure and personnel. ${ }^{17,18}$

To better understand the barriers to improving awareness of AKI in developing countries, a questionnaire was developed by a group of 20 nephrologists during the 2014 International Society of Peritoneal Dialysis (ISPD) meetings in Madrid. These nephrologists included physicians from sub-Saharan Africa, Southeast Asia, North and South 
America, and Europe, all of whom had experience working in developing countries. Of 26 respondents, there were 54\% from Africa, 19\% from the Americas, $12 \%$ from South Asia, and $12 \%$ from the Western Pacific. ${ }^{19}$

There were substantial variations noted in available therapies and diagnostic capabilities when comparing rural health centers, district health centers, and regional health centers. Therapies available for the initial diagnosis and management of AKI appear to be limited in rural health centers, because $84 \%$ of respondents indicated that the diagnosis of AKI in this setting is mostly made on the basis of clinical judgment, reflecting limited availability of laboratory services. Only $60 \%$ of respondents indicated that these rural health centers have intravenous fluids and only 52\% indicated that they have appropriate antibiotic therapy to treat infection-related AKI. Based on survey responses, oral rehydration solutions appear to be available in virtually all rural health centers and antimalarial drugs in $88 \%$ of rural health centers. Antivenom therapy is generally not available in rural communities. ${ }^{19}$

All district health centers had oral rehydration solutions and $96 \%$ indicated that intravenous fluids and antimalarial drugs are readily available, $72 \%$ of respondents indicated that appropriate antibiotics are available in the district health centers, and $63 \%$ indicated that appropriate laboratory support is available to diagnose AKI. No respondents indicated that dialysis therapies are available. ${ }^{19}$

In regional health centers, oral and intravenous fluid replacement and antibiotics, including antimalarial agents, are available, and $84 \%$ of respondents indicated that appropriate laboratory support is available to make a diagnosis of AKI. Dialysis therapy for AKI is available in only select regional health centers, with limited availability reflecting a frequent lack of qualified nurses or physicians, as well as a lack of available hemodialysis (HD) or peritoneal dialysis (PD) machines or supplies. If the appropriate equipment was available, patients would generally be required to pay for such services, rendering even time-limited dialysis therapies out of reach for the vast majority of patients.

A recent study described the availability and quality of laboratory services in Africa. Most of the countries (37 of 49) had no laboratories accredited to international quality standards. ${ }^{18}$ Moreover, the laboratory services that were available were generally available only in large urban centers. Additional challenges to treat patients with AKI include delays in patients seeking health care and an inability of patients to get to and pay for it. For example, during the earthquake in Haiti in January 2010, only 19 patients were referred to the Renal Disaster Relief Task Force in Port-au-Prince despite $>300,000$ casualties. ${ }^{20}$
Tragically, people continue to die in large numbers in developing countries as a result of this disorder, which in many cases is preventable and potentially treatable with simple measures. Individuals with AKI who progress to the stage at which RRT would be indicated die because dialysis is simply not available or affordable. This is unacceptable because patients have an excellent chance of survival when the kidney is given enough time to recover and life is sustained by dialysis. Unfortunately, few epidemiological data exist for outcomes of AKI in developing countries, which makes it difficult to describe the context of this disorder in these countries.

This shortcoming is highlighted well in the study by Olowu et al. ${ }^{21}$ This systematic review of AKI, with a focus on sub-Saharan Africa, documents that, in 3,340 patients admitted to hospital with AKI in 13 countries in the region, the disorder was severe in most cases, with indications for dialysis in $66 \%$ of children and $70 \%$ of adults. However, only slightly more than half of children and one-third of adults received dialysis when required.

Although the studies analyzed were of low quality, these findings confirm what has been reported in other LRSs worldwide. Indeed, one concern in LRSs is that people often present late to hospital or large referral health care centers, which suggests more severe AKI at admission, a greater need for dialysis, and an increased risk of death compared with higher-income countries. Since AKI is not associated with any specific symptoms, and diagnosis is largely based on laboratory measurements, which are rarely available in remote areas, it often goes unrecognized during a first examination by nonspecialist health care providers.

Caregivers in the community might not have the knowledge for early recognition, timely intervention, and effective follow-up. Thus, training primary care physicians and other health caregivers to raise awareness, share knowledge, and provide practical management of AKI is imperative in developing countries, where nurses and allied health personnel should also play a key part in building the workforce to recognize and care for people with AKI. This role is particularly important since the density of physicians is $0.02-0.29$ per 1,000 people in many African countries, which is ten to 100 times lower than the target of the World Health Organization. ${ }^{22}$

The study by Olowu et $\mathrm{al}^{21}$ also showed that $\sim 80 \%$ of children and adults with AKI in sub-Saharan Africa who required, but did not receive, dialysis die. Major barriers to access to care were erratic hospital resources and out-ofpocket costs. Dialysis treatment is often thought to be too 
costly and complex to be delivered in LRSs. In low-income and often in middle-income countries, renal replacement programs are accessible only in large cities, usually only for patients who can afford to pay for treatment and are often not situated in acute care hospitals. Thus, patients who develop AKI and are in need of dialysis support often die. Dialysis might reduce mortality related to AKI in resource-limited settings, but acute HD is not easily affordable because of the high cost of machines and consumables, unreliable electricity and water supplies, and scarcity of trained personnel. ${ }^{23}$

By contrast, gravity-driven PD is a more realistic option because RRT can be delivered without machines and electricity, relying only on consumable supplies, and thus reducing costs and complexity in LRSs. ${ }^{24}$ Although particularly useful in areas with fragile health infrastructure, PD is underused in most parts of the world, despite advantages such as reasonable costs (as little as US\$150 to save one life) in remote locations. ${ }^{25}$ This approach is feasible documented by encouraging results from ongoing $\mathrm{PD}$ programs for $\mathrm{AKI}$ in selected centers in Africa and Asia. ${ }^{26-28}$

\section{The Saving Young Lives program}

Framing AKI as a driver of substantial inequity in disease risk and mortality in developing countries, the ISN has created and launched the multifaceted human rights program " 0 by 25 ", which advocates that no one should die of untreated AKI, with a focus on low- and middle-income countries in Africa, Asia, and Latin America. ${ }^{26}$

This ongoing program encompasses building human capacities through education and training at all levels of health care systems, coupled with making point-of-care AKI diagnostic tools and AKI management available at a low cost. ${ }^{2}$ However, the success of this and other initiatives ultimately rests on the capacity of national health authorities to adopt and ensure the sustainability of AKI programs, making access to acute RRT with dialysis affordable for those in need, with the hope of substantially curtailing mortality associated with treatable AKI in developing countries worldwide.

For this initiative, under the project leadership of Ravindra Mehta, the ISN has developed a multifaceted integrated program with globally applicable strategies. They will operate at three levels, first to establish AKI as a contributor to global burden of diseases. It will be pursued by collection of existing data and prospectively collected evidence. To address this issue, the 0 by 25 initiative has launched the "AKI Global Snapshot", a prospective observational cohort study to compare risk factors, etiologies, diagnosis, management, and outcomes of AKI, the results of which was presented at the World Congress of Nephrology 2015 meeting in Cape Town. A follow-up longitudinal "AKI Cohort Study" was also initiated in selected centers across the world during 2015 to capture sequential data on AKI and its long-term consequences. Second, the aim is to raise awareness of AKI in the worldwide community. In this article, the target audience will be health care professionals, patients, academic researchers, worldwide organizations and foundations, country governments, politicians, as well as scientific societies. Finally, they would like to develop a sustainable infrastructure to enable "need-driven" approaches for education and training, care delivery, and measurable outcomes. This approach will be tested in pilot studies in selected centers in developing countries with the aim of rapidly scaling up the lessons learned for broader adoption at national and regional levels. The program is implemented according to five strategic components representing the 5R approach as detailed in Figure 1.

The Saving Young Lives program was started in 2012 and has been providing financial and educational support to develop PD therapy for patients with AKI in developing countries. ${ }^{6,7,27}$ In these settings, the advantages of PD over HD include medical and technical simplicity and the lack of need for electricity, machinery, and pure water, among other factors. ${ }^{29}$

Importantly, excellent outcomes have been observed when using PD to treat patients with AKI. ${ }^{6,7,23,27,29}$ Within this team effort, the international societies help provide education, training support for health care workers, and supplies. To date, successful programs have been developed at ten sites in eight countries, with three additional sites in development as of late 2015 .

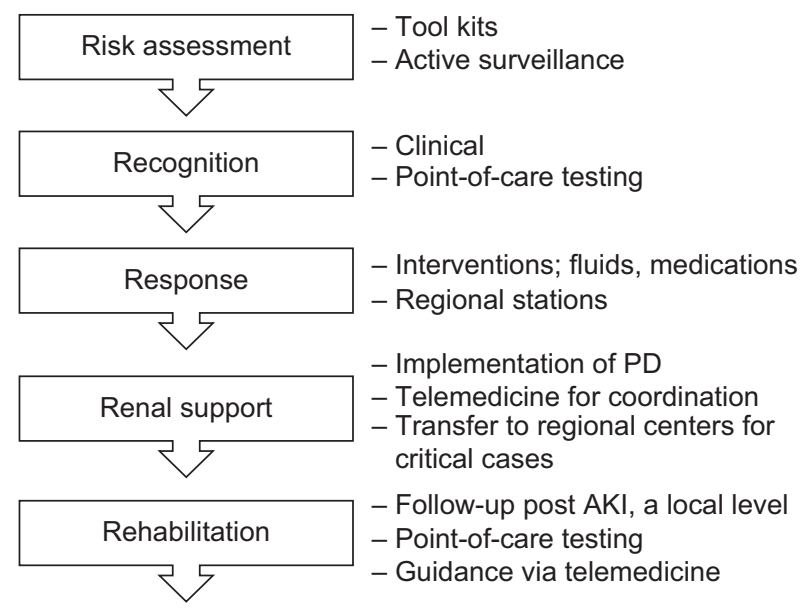

Figure I The 5R approach for a sustainable AKI program by the ISN 0 by 25 initiative. Abbreviations: AKI, acute kidney injury; ISN, International Society of Nephrology; $\mathrm{PD}$, peritoneal dialysis. 
This project addresses one aspect of the spectrum of providing support for AKI programs and has shown that PD therapy is feasible and can be provided at a low cost with acceptable outcomes and perhaps, most importantly, that various international organizations, nongovernmental organizations, and local hospitals can collaborate to develop successful treatments for AKI. ${ }^{6,720}$

\section{PD as a viable option for $A K I$ in developing countries}

PD has a number of advantages over other therapies; some of which are proven and others hypothetical. Certainly, it has been well demonstrated that acute PD requires less infrastructure and training than extracorporeal therapies, but has also been shown to be more cost effective. Two studies ${ }^{6,7}$ from India showed that acute PD costs approximately half of the cost for HD or continuous venovenous hemofiltration (CVVH), and Kilonzo et $\mathrm{al}^{7}$ showed that it costs $\sim$ US\$350 for every life saved when using manual acute PD with two hourly exchanges.

Since no extracorporeal circulation is required, there is relatively good hemodynamic tolerance, and local renal hemodynamics may be better preserved. It has also been postulated that PD may be more physiologic and less inflammatory than extracorporeal therapies, which involve the exposure of blood to synthetic membranes. These factors together could potentially contribute to earlier recovery of renal function seen in some studies. ${ }^{30}$

\section{Technical aspects}

It should be recognized that the volumes of fluid used in acute PD are significantly greater than those used in chronic patients. Thus, flow rates need to be high and the catheter used needs to be able to cope with this. For this reason, flexible PD catheters (eg, Tenckhoff catheter) have an advantage as they have a larger diameter lumen and side holes than the rigid catheters.

The second advantage of these catheters is that they can be tunneled and if the patient has prolonged AKI or proves to have chronic kidney disease, they have no need for a further access device. Tunneling of the catheters may also prevent leakage of dialysate. The drawback of these catheters is that they need to be inserted using a peel-away sheath dilator at the bedside or be inserted surgically. This reduces the uptake of these catheters as training clinicians to insert these catheters takes time and is often not available in the low-resource countries that rely so heavily on PD for treating AKI.

Initiatives such as Saving Young Lives Campaign and industry-sponsored training sessions are improving knowledge in these areas; however, the task remains enormous. It is for this reason that other catheters are often used that may not have the same efficacy but are still certainly lifesaving. The rigid stylet catheter, which is introduced with the aid of a trocar through a skin incision subumbilically, is perhaps the easiest catheter to insert and the most widely used non-tunneled catheter. However, it has major drawbacks: first, it is produced from rigid nylon and has been reported to erode into the bowel and other intra-abdominal organs. The catheters often become obstructed with fibrin and need regular flushing by nursing staff. This break in the sterile circuit may explain the higher rates of peritonitis seen with these catheters compared with flexible catheters. ${ }^{31}$ The fluid flow rate will also be compromised by this intermittent obstruction. The catheters cost approximately one-tenth that of the flexible catheters, something that makes them more appealing in a low-resource environment.

Clinicians in resource-poor areas with limited access to catheters have saved many lives using makeshift catheters such as modified nasogastric tubes and intercostal drains. ${ }^{32}$

The ISPD guidelines strongly recommend that flexible PD catheters are inserted at the bedside by nephrologists to prevent delays in initiating acute PD while waiting for theater time, etc. It has been shown in programs where nephrologists insert catheters for chronic PD that PD uptake increases in that unit. It would seem reasonable that the same would occur for acute PD as well. ${ }^{33}$

The fluid delivery method used has the potential to impact on the incidence of peritonitis in patients on acute PD as there are significantly more connections and disconnections compared with the three to four exchanges in chronic PD.

Automated cycler PD employs a mechanized device to deliver and drain the dialysate. The advantage of this system is that it can be set up by a trained staff member once per day to reduce the risk of complications, especially contamination by inexperienced members of staff. It also reduces nursing time, especially on the intensive care unit, as all cycles are automatic. There are conflicting reports of whether there is a reduction in peritonitis with cyclers but on balance there appears to be no difference compared with the manual system in chronic PD. Another benefit is that they can offer tidal $\mathrm{PD}$, where a small volume of fluid is left in the abdomen at all times which may reduce mechanical complications and may reduce pain associated with complete fluid drainage. Occasionally, however, the fixed hydraulic suction may worsen the mechanical obstruction in catheters with already tenuous fluid flow. Tidal PD has the added theoretical benefit that fluid is continually dwelling in the peritoneal space even 
during the fill and drain portion of the cycle thus increasing solute clearance.

Automated cyclers have been used extensively for PD in AKI; however, in a resource-poor setting, cyclers may prove too expensive. ${ }^{30,34} \mathrm{~A}$ further disadvantage of cyclers is that if there is no support after hours for inexperienced nurses using the cyclers, there is the risk of the machines being turned off during the night to avoid alarms.

The ISPD guidelines recommend the use of commercially produced PD solutions as these solutions are tested to high standards of sterility. It is clear, however, that in many resource-poor countries where acute PD is offered, the acquisition of this fluid ranges from difficult to impossible. As fluid is too heavy to be delivered by air, it must often pass through a number of countries before reaching its destination. There are often levies imposed, legal or illegal, which make the cost of the fluid prohibitive. As a result, a number of PD units have been making up their own solutions using a mixture of modified Ringer's lactate and glucose, both of which are readily available in most hospitals. However, the drawback of this is the risk of peritonitis and the fact that there is a small amount of potassium in the solution. A recent presentation from the Saving Young Lives site in Cameroon showed that using locally mixed fluids they had only one peritonitis episode in 38 cases. $^{35}$

\section{PD outcomes in AKI}

With the increasing interest in using PD to manage patients with $\mathrm{AKI},{ }^{35-43}$ the first question that must be asked is whether PD can provide adequate clearance in the treatment of these patients. $^{44,45}$

The optimal prescription of dialysis in AKI is hampered by our lack of understanding of the exact factors that influence survival. We know that hyperkalemia, acidosis, and massive fluid overload need to be treated. After these are corrected, the issue of whether we focus on the removal of small molecules (eg, urea and creatinine) or larger molecule clearances (eg, cytokines and soluble receptors) is uncertain.

According to the ISPD guidelines regarding PD for AKI, where resources permit, targeting a weekly Kt/V urea of 3.5 provides outcomes comparable to that of daily HD; targeting higher doses does not improve outcomes. This may not be necessary for many patients with AKI and targeting a weekly $\mathrm{Kt} / \mathrm{V}$ of 2.1 may be acceptable; however, this is not evidence based. ${ }^{42,44}$

The next question is whether PD is comparable to other dialysis methods in patients with AKI. The answer to that question is neither simple nor currently complete. Despite a significant attempt to find the optimal therapy, the average mortality of patients with AKI has not been clearly seen to improve in recent years. ${ }^{46,47}$ However, we should nevertheless clarify that advances in technology now allow for the treatment of high-risk patients in whom RRTs were precluded or contraindicated in the past. ${ }^{46-48}$ The various modalities of acute RRT present advantages and disadvantages under specific circumstances; the spectrum of therapies for AKI should therefore be considered more as a continuum than as a series of modalities to be compared, one to the other.

Few studies have compared PD with other dialysis methods in patients with AKI, and reports conflict with regards to efficacy and cost. Phu et $\mathrm{al}^{49}$ compared intermittent PD with continuous RRT, and they demonstrated a worse outcome in patients treated with PD. This study was stopped early due to a higher mortality in the PD arm, thus only randomizing 35 patients to each group. Apart from criticisms of the method of PD and high peritonitis rate, this study of acutely ill patients with sepsis or malaria showed that with CVVH the mortality was only $15 \%$, which is far lower than the mortality seen in most intensive care units offering CVVH. ${ }^{50}$

George et $\mathrm{al}^{47}$ performed a randomized study to compare CVVH and continuous PD in critically ill patients. No difference was observed in correction of metabolic parameters and fluid overload. Urea and creatinine clearances were higher and fluid correction was faster with CVVH. The mortality rates in the two study groups were similar. Unfortunately, the study was underpowered and performed using both peritoneal and CVVH clearances below which one would consider optimal. Along with these rigid catheters, locally available PD fluids and manual exchanges were used. Despite this, PD mortality was lower than CVVH (nonsignificant).

A randomized study performed in Brazil with 120 patients with AKI, compared high-volume PD (HVPD) vs daily intermittent HD. ${ }^{30}$ Baseline characteristics were similar in both groups, which included older patients (mean age $>60$ years), high Acute Physiologic Assessment and Chronic Health Evaluation II scores, and vasoactive drugs use (>60\%). Both RRT modalities achieved metabolic and acid-base control. Mortality did not differ significantly between the two groups $(58 \%$ vs $53 \%, P=0.48)$. The rate of renal recovery was similar for both modalities, but HVPD was associated with a significantly shorter time to recovery (7.2 \pm 2.6 days vs $10.6 \pm 4.7$ days).

In another prospective study comparing the effect of HVPD and prolonged HD (PHD) on AKI patients' outcome, ${ }^{51}$ the PHD and HVPD groups were similar in sex, disease severity scores, and etiology of AKI. There was a trend toward statistical difference regarding the presence of sepsis $(62.3 \%$ in the PHD 
group vs $44.9 \%$ in the HVPD group, $P=0.054)$. Delivered $\mathrm{Kt} / \mathrm{V}$ and ultrafiltration were higher in the PHD group; however, there was no difference between the two groups in mortality and recovery of kidney function or need for chronic dialysis.

Al Hwiesh et $\mathrm{al}^{52}$ in Saudi Arabia recently presented a randomized controlled trial of tidal automated $\mathrm{PD}$ compared with CVVH. The dose of hemofiltration was in keeping with international standards; however, metabolic control appeared to be less efficient than one would expect for the filtration rates achieved. They used tidal automated PD with biocompatible solutions which differs from most of the studies of HVPD. The primary end point of 28-day survival was significantly higher in the PD group $(69.8 \%$ vs $46.8 \%, P<0.01)$.

A systematic review published by Chionh et $\mathrm{al}^{53}$ concluded that there is currently no evidence to suggest significant differences in mortality between PD and extracorporeal blood purification in AKI and there is a need for good-quality evidence in this important area.

Nevertheless, a successful program's flexibility and creativity was demonstrated when, after 25 patients were dialyzed and the program no longer had the funds to purchase new supplies, the physicians decided to make their own solutions, following recently published in-depth guidelines. ${ }^{30}$

Finally, PD is a simple, safe, and efficient way to correct metabolic, electrolyte, acid--base, and volume disturbances generated by AKI and it can be used as an RRT modality to treat AKI, both in and out the intensive care unit setting. Recent reports have shown that in units regularly performing PD for AKI, mortality and complication rates have fallen further and there is no reason to believe that other modalities offer any outcome benefit over PD. It remains to be shown whether the more rapid recovery of renal function seen with acute $P D$ has a long-term overall benefit compared with other modalities. The ISPD have firmly recommended that PD is a suitable modality for treating patients with AKI, mainly in developing countries.

\section{Conclusion}

There is a critical need to address AKI in developing countries. In their 0 by 25 initiative, the ISN has challenged both the nephrology community and the broader health care community to work collaboratively to develop effective programs to treat AKI in developing countries. The demands for health care in low-resource regions and in many low- to middle-income countries are changing. Ensuring access to clean water and sanitation, battling ongoing communicable diseases, and stemming the tide of preventable deaths such as those due to AKI should dominate the attention of those driving the health care agenda in many resource-poor nations. The hope is that the ISN could catalyze an acceleration of these much-needed changes by undertaking, over the next decade, a focused effort to markedly curtail treatable AKI-associated mortality and to improve health care outcome globally, especially in poor countries. In developing world, the advantages of PD over HD include medical and technical simplicity and the lack of need for electricity, machinery, and pure water, among other factors. Initiatives such as Saving Young Lives Campaign and industry-sponsored training sessions are improving knowledge in these areas; however, the task remains enormous.

Going forward, many challenges need to be considered. Awareness of AKI in local, district, and regional health care centers needs to be improved. We suggest that this will require a multifaceted approach, involving the nephrology community, government officials, hospital administrators, physicians, nurses, and local health care workers. Meaningful educational programs, training materials, and treatment guidelines should be developed and alliances should be formed with governmental agencies, nonprofit organizations, global health programs, community organizations, international and local nephrology organizations, and local champions if this initiative is going to be successful.

\section{Disclosure}

The authors report no conflicts of interest in this work.

\section{References}

1. Lameire NH, Bagga A, Cruz D, et al. Acute kidney injury: an increasing global concern. Lancet. 2013;382(9887):170-179.

2. Mehta RL, Cerdá J, Burdmann EA, et al. International Society of Nephrology's 0by25 initiative for acute kidney injury (zero preventable deaths by 2025): a human rights case for nephrology. Lancet. 2015;385(9987):2616-2643.

3. Lewington A, Cerda J, Mehta RL. Raising awareness of acute kidney injury: a global perspective of a silent killer. Kidney Int. 2013;84(3):457-467.

4. Susantitaphong P, Cruz DN, Cerda J, et al. World incidence of AKI: a meta-analysis. Clin J Am Soc Nephrol. 2013;8(9):1482-1493.

5. Cerda J, Lameire N, Eggers P, et al. Epidemiology of acute kidney injury. Clin J Am Soc Nephrol. 2008;3(3):881-886.

6. Finkelstein FO, Smoyer WE, Carter M, Brusselmans A, Feehally J. dialysis, acute kidney injury, and the Saving Young Lives program. Perit Dial Int. 2014;34(5):478-480.

7. Kilonzo KG, Ghosh S, Temu SA, et al. Outcome of acute peritoneal dialysis in northern Tanzania. Perit Dial Int. 2012;32(3):261-266.

8. Schieppati A, Perico N, Remuzzi G. Eliminating treatable deaths due to acute kidney injury in resource-poor settings. Semin Dial. 2015;28(2):193-197.

9. Chertow GM, Burdick E, Honour M, Bonventre JV, Bates DW. Acute kidney injury, mortality, length of stay, and costs in hospitalized patients. J Am Soc Nephrol. 2005;16(11):3365-3370.

10. Jha V, Parameswaran S. Community-acquired acute kidney injury in tropical countries. Nat Rev Nephrol. 2013;9(5):278-290.

11. Bagasha P, Nakwagala F, Kwizera A, Ssekasanvu E, Kalyesubula R. Acute kidney injury among adult patients with sepsis in a low-income country: clinical patterns and short-term outcomes. BMC Nephrol. 2015;16:4.

12. Krishnamurthy S, Mondal N, Narayanan P, Biswal N, Srinivasan S, Soundravally R. Incidence and etiology of acute kidney injury in southern India. Indian J Pediatr. 2013;80(3):183-189. 
13. Mehta P, Sinha A, Sami A, et al. Incidence of acute kidney injury in hospitalized children. Indian Pediatr. 2012;49(7):537-542.

14. Xue JL, Daniels F, Star RA, et al. Incidence and mortality of acute renal failure in Medicare beneficiaries, 1992 to 2001. J Am Soc Nephrol. 2006; 17(4):1135-1142.

15. Esezobor CI, Ladapo TA, Osinaike B, Lesi FE. Pediatric acute kidney injury in a tertiary hospital in Nigeria: prevalence, causes and mortality rate. PLoS One. 2012;7(12):e51229.

16. Couser WG, Remuzzi G, Mendis S, Tonelli M. The contribution of chronic kidney disease to the global burden of major noncommunicable diseases. Kidney Int. 2011;80(12):1258-1270.

17. Anand S, Cruz DN, Finkelstein FO. Understanding acute kidney injury in low resource settings: a step forward. BMC Nephrol. 2015;16:5.

18. Schroeder LF, Amukele T. Medical laboratories in sub-Saharan Africa that meet international quality standards. Am J Clin Pathol. 2014;141(6): 791-795.

19. Lunyera J, Kilonzo K, Lewington A, Yeates K, Finkelstein FO. Acute kidney injury in low-resource settings: barriers to diagnosis, awareness, and treatment and strategies to overcome these barriers. Am J Kidney Dis. 2016;67(6):834-840.

20. Remillard BD, Buteau JH, Cléophat P. Kidney care in Haiti - the role of partnerships. Nat Rev Nephrol. 2015;11(3):183-188.

21. Olowu WA, Niang A, Osafo C, et al. Outcomes of acute kidney injury in children and adults in sub-Saharan Africa: a systematic review. Lancet Glob Health. 2016;4(4):e242-e250.

22. Kinfu Y, Dal Poz MR, Mercer H, Evans DB. The health worker shortage in frica: are enough physicians and nurses being trained? Bull World Health Organ. 2009;87(3):225-230.

23. Ponce D, Berbel MN, Regina de Goes C, Almeida CT, Balbi AL. High-volume peritoneal dialysis in acute kidney injury: indications and limitations. Clin J Am Soc Nephrol. 2012;7(6):887-894.

24. Prabhu MV, Subhramanyam SV, Sinoj KA, Nayak KS. Manual acute PD with rigid catheters - a relook. Open Uroland Nephrol J. 2015;8:31-38.

25. Remuzzi G, Horton R. Acute renal failure: an unacceptable death sentence globally. Lancet. 2013;382(9910):2041-2042.

26. Perico N, Remuzzi G. Acute kidney injury in low-income and middleincome countries: no longer a death sentence. Lancet 2016; e216-e2174(4)

27. Callegari Kidney Int, Callegari JG, Kilonzo KG, et al. Peritoneal dialysis for acute kidney injury in sub-Saharan Africa: challenges faced and lessons learned at Kilimanjaro Christian Medical Centre. Kidney Int. 2012; 81(4):331-333.

28. Abdelraheem M, Ali el -T, Osman R, et al. Outcome of acute kidney injury in Sudanese children - an experience from a sub-Saharan African unit. Perit Dial Int. 2014;34(5):526-533.

29. Cullis B, Abdelraheem M, Abrahams G, et al. Peritoneal dialysis for acute kidney injury. Perit Dial Int. 2014;34(5):494-517.

30. Gabriel DP, Caramori JT, Martim LC, Barretti P, Balbi AL. High volume peritoneal dialysis vs daily hemodialysis: a randomized, controlled trial in patients with acute kidney injury. Kidney Int Suppl. 2008;73(108): S87-S93.

31. Wong SN, Geary DF. Comparison of temporary and permanent catheters for acute peritoneal dialysis. Arch Dis Child. 1988;63(7):827-831.

32. Goh B, Ganeshadeva Y, Chew S, Dalimi M. Does peritoneal dialysis catheter insertion by interventional nephrologists enhance peritoneal dialysis penetration. Semin Dial. 2008;21(6):561-566.
33. Nyah N. Oral Communication. Dakar, Senegal: West African Dialysis Congress; 2015.

34. Ponce D, Berbel MN, Almeida CTP, Goes CR, Balbi AL. High volume peritoneal dialysis in acute kidney injury: indications and limitations. Clin J Am Soc Nephrol. 2012;7(6):887-894.

35. Rao P, Passadakis P, Oreopoulos DG. Peritoneal dialysis in patients with acute renal failure. Perit Dial Int. 2003;23(4):320-322.

36. Gabriel DP, Nascimento GV, Caramori JT, Martim LC, Barretti P, Balbi AL. Peritoneal dialysis in acute renal failure. Ren Fail. 2006;28(6):451-456.

37. Gabriel DP, Fernandez-Cean J, Balbi AL. Utilization of peritoneal dialysis in the acute setting. Perit Dial Int. 2007;27(3):328-331.

38. Davenport A. Peritoneal dialysis in acute kidney injury. Perit Dial Int. 2008;28(4):423-424.

39. Ash SR. Peritoneal dialysis in acute renal failure of adults: the underutilized modality. Contrib Nephrol. 2004;144:239-254.

40. Ponce D, Banin VB, Bueloni TN, Barretti P, Caramori J, Balbi AL. Different outcomes of peritoneal catheter percutaneous placement by nephrologists using a trocar versus the Seldinger technique: the experience of two Brazilian centers. Int Urol Nephrol. 2014;46(10):2029-2034.

41. Passadakis PS, Oreopoulos DG. Peritoneal dialysis in patients with acute renal failure. Adv Perit Dial. 2007;23:7-16.

42. Chionh CY, Ronco C, Finkelstein FO, Soni SS, Cruz DN. Acute peritoneal dialysis: what is the 'adequate' dose for acute kidney injury? Nephrol Dial Transplant. 2010;25(10):3155-3160.

43. Kronfol N. Acute peritoneal dialysis prescription. In: Daugirdas JT, Ing TS, editors. Handbook of Dialysis. 2nd ed. Boston: Little, Brown and Company; 1994:301-309.

44. Chionh CY, Soni S, Cruz DN, Ronco C. Peritoneal dialysis for acute kidney injury: techniques and dose. Contrib Nephrol. 2009;163:278-284.

45. Chitalia VC, Almeida AF, Rai H, et al. Is peritoneal dialysis adequate for hypercatabolic acute renal failure in developing countries? Kidney Int. 2002;61(2):747-757.

46. Ronco C. Can peritoneal dialysis be considered an option for the treatment of acute kidney injury? Perit Dial Int. 2007;27(3):251-253.

47. George J, Varma S, Kumar S, Thomas J, Gopi S, Pisharody R. Comparing continuous venovenous hemodiafiltration and peritoneal dialysis in critically ill patients with acute kidney injury: a pilot study. Perit Dial Int. 2011; 31(4):422-429.

48. Ponce D, Caramori JTC, Barretti P, Balbi AL. Peritoneal dialysis in acute kidney injury: Brazilian experience. Perit Dial Int. 2012;32(3):242-246.

49. Phu NH, Hien TT, Mai NT, et al. Hemofiltration and peritoneal dialysis in infection-associated acute renal failure in Vietnam. N Engl J Med.2002; 347(12):895-902.

50. Uchino S, Kellum J, Bellomo R, et al. Acute renal failure in critically ill patients. A multinational, multicenter study. JAMA. 2005;294(7):813-818.

51. Ponce D, Berbel MN, Abrão JM, Goes CR, Balbi AL. A randomized clinical trial of high volume peritoneal dialysis versus extended dailyhemodialysis for acute kidney injury patients. Int Urol Nephrol. 2013;45(3):869-878.

52. Al Hwiesh A. Tidal PD versus CVVF in AKI patients: a randomized controlled trial. Presented at: Congress of the Arab Society of Nephrology; 2014; Saudi Arabia.

53. Chionh CY, Soni SS, Finkelstein FO, Ronco C, Cruz DN. Use of peritoneal dialysis in AKI: a systematic review. Clin J Am Soc Nephrol. 2013; 8(10):1649-1660.

\section{Publish your work in this journal}

The International Journal of Nephrology and Renovascular Disease is an international, peer-reviewed open access journal focusing on the pathophysiology of the kidney and vascular supply. Epidemiology, screening, diagnosis, and treatment interventions are covered as well as basic science, biochemical and immunological studies. The manuscript
Dovepress

management system is completely online and includes a very quick and fair peer-review system, which is all easy to use. Visit http://www. dovepress.com/testimonials.php to read real quotes from published authors. 